\title{
CINÉTICA DE LIBERAÇÃO DE POTÁSSIO EM SOLOS DO RIO GRANDE DO SUL ${ }^{(1)}$
}

\author{
E. J. MEURER ${ }^{(2)}$ \& J . I. ROSSO(3)
}

\begin{abstract}
RESUMO
Estudos sobre cinética de dessorção de potássio em solos podem contribuir para o melhor entendimento da disponibilidade desse nutriente no solo para as plantas. Este trabalho, realizado em 1993, teve por objetivos investigar a cinética de liberação de potássio em três solos do Rio Grande do Sul e comparar quatro equações para descrevê-la. 0 experimento utilizou amostras superficiais $(0-20 \mathrm{~cm})$ dos horizonte A de um vertissolo, de um podzólico e de um latossolo. A dessorção do potássio foi quantificada desde um minuto até $\mathbf{2 . 4 0 0}$ horas, usando-se resina trocadora de cátions (I R-120). O K trocável nos três solos foi liberado em 12 minutos de equilíbrio com a resina $\mathrm{H}$-saturada. As quantidades cumulativas de potássio não-trocável li beradas dos solos decresceram, na seqüência vertissolo (436 mg kg ${ }^{1}$ de K) > podzólico (64 mg kg-1 de K) >latossolo (46 mg kg-1 de K). A equação parabólica de difusão foi a mais apropriada para descrever a cinética de liberação do potássio não-trocável dos solos, pelo maior valor do coeficiente de correlação e pelo menor valor do erro-padrão da estimativa. As taxas de liberação do potássio não-trocável dos solos, estimadas por esta equação, foram de $2,09 \times 10^{-2} \mathrm{~h}^{-1}$, para o vertissolo; de $1,89 \times 10^{-2} \mathrm{~h}^{-1}$, para o podzólico, e de $0,97 \times 10^{-2} \mathrm{~h}^{-1}$, para o latossolo.
\end{abstract}

Termos de indexação: potássio não-trocável, equação de difusão, ci nética, potássio.

\section{SUMMARY: KINETICS OF POTASSIUM RELEASE FROM SOILS OF THE STATE OF RIO GRANDE DO SUL, BRAZIL}

Kinetics studies of potassium release from soils can improve our knowl edge about its availability to plants. Thepresent study, carried out in 1993, was undertaken to investigatethe kinetics of potassium release and to compare four kinetics equations to describe the K-rel ease from three soils of the State of Rio Grande do Sul, Brazil. Samples of A horizons of a Vertisol, of an UItisol and of an Oxisol, wereequilibrated with a cation exchangeresin (IR-120) from one minute up to 2,400 hours. Exchangeable potassium was totally rel eased to the $\mathrm{H}$-saturated resin in 12 minutes in all soils. The cumulative amounts of non-exchangeableK released from

\footnotetext{
(1) Recebido para publicação em novembro de 1996 e aprovado em outubro de 1997.

(2) Professor Adjunto do Departamento de Solos, Faculdade de Agronomia, UFRGS. Caixa Postal 776, CEP 90001-970 Porto Alegre (RS). Bolsista do CNPq.

(3) Estudante do Curso de Pós-Graduação em Ciência do Solo do Programa de Pós-Graduação em Agronomia da Faculdade de Agronomia, UFRGS. Caixa Postal 776, CEP 90001-970 Porto Alegre (RS).
} 


\begin{abstract}
soils decreased in thesequenceVertisol ( $\left.436 \mathrm{mg} \mathrm{kg}^{-1} \mathrm{~K}\right)>$ Ultisol $\left(64 \mathrm{mg} \mathrm{kg}^{-1} \mathrm{~K}\right)>0$ Oxisol $\left(46 \mathrm{mg} \mathrm{kg}^{-1} \mathrm{~K}\right)$. The parabolic diffusion equation described the data satisfactorily as shown by the highest correlation coefficient and the lowest standard error of the estimate Coefficients for nonexchangeableK release rate were $2.09 \times 10^{-2} \mathrm{~h}^{-1}$ for the Vertisol, $1.89 \times 10^{-2} \mathrm{~h}^{-1}$ for the Ultisol and $0.97 \times 10^{-2} \mathrm{~h}^{-1}$ for the Oxisol.
\end{abstract}

Index terms: non-exchangeable potassi um, diffusi on equation, kinetics, potassium.

\section{INTRODUÇÃO}

O potássio, extraído do solo com soluções de $\mathrm{NH}_{4} \mathrm{OAc} 1 \mathrm{~mol} \mathrm{~L}^{-1}$ ou de Mehlich-1 ( $\mathrm{K}$ trocável), é considerado como a principal fração do nutriente que está disponível para a absorção pelas plantas, principalmente nos solos muito intemperizados dos trópicos. Entretanto, verificou-se que formas nãotrocáveis de potássio também podem contribuir, expressivamente, nesses solos, para o suprimento do potássio às plantas (Crisóstomo \& Castro, 1970; Oliveira et al., 1971; Mielniczuk \& Selbach, 1978; Nachtigall \& Vahl, 1991; Silva et al., 1995).

Em latossolos do Estado do Paraná, onde foi verificada a ocorrência de micas e minerais 2:1 com hidroxi-Al entrecamadas (Silva et al. 1995), observouse a contribuição de formas não-trocáveis de potássio a culturas de trigo-soja cultivadas em sucessão durante dez anos. Em solos do E stado do Rio Grande do Sul, foram encontradas fontes potenciais de potássio para as plantas, em formas não-trocáveis (Meurer et al., 1996).

Nos últimos anos, os estudos de disponibilidade de potássio do solo têm enfatizado a necessidade da quantificação das taxas com que o potássio é li berado das formas não-trocáveis para as plantas (Martin \& Sparks, 1985; Elkhatib \& Hern, 1988; Dhillon et al., 1989; Comerford et al., 1990; Simard et al ., 1992). Tais informações poderão melhorar a predição da disponi bilidade do potássio no sol o e as recomendações deadubação potássica. Apesar da importância desses estudos, existe pouca informação para solos das regiões tropicais. Resinas trocadoras de cátions saturadas com prótons têm sido utilizadas para estudar a cinética de liberação de potássio em solos (Kauffman \& Bouldin, 1967; Martin \& Sparks, 1983; Martin \& Sparks, 1985; Dhillon \& Dhillon, 1990). Elas apresentama vantagem denão dissolver as estruturas dos minerais, como acontece quando ácidos fortes são usados.

Diversas equações matemáticas têm si do utilizadas para descrever a cinética de adsorção e liberação de potássio do solo. As mais comuns são as de primeiraordem, a de Elovich, a parabólica de difusão e a da função potência, cujas características e aplicações estão detalhadas em Sparks (1989).

Este trabalho objetivou investigar a cinética de liberação de potássio em três solos do Rio Grande do Sul, com diferentes características mineralógicas, e comparar quatro equações para descrevê-la.

\section{MATERIAL E MÉTODOS}

Utilizaram-se amostras $(0-20 \mathrm{~cm})$ do horizonte A de um vertissolo (unidade Aceguá), de um podzólico (unidade São J erônimo) e de um latossolo roxo (unidade Santo Ângelo) do Estado do Rio Grande do Sul (Brasil, 1973), cujas características gerais se encontram no quadro 1 . Os principais minerais encontrados nas frações granulométricas estão relacionados no quadro 2, e maiores detalhes da mineralogia desses solos podem ser encontrados em Meurer et al. (1996). O pH em água, o teor de $\mathrm{P}$ extraível, o teor de matéria orgânica e a capacidade de troca de cátions (CTC) foram determinados, conforme descrito em Tedesco et al . (1985). O potássio foi extraído por solução de $\mathrm{NH}_{4} \mathrm{OAc} 1 \mathrm{~mol} \mathrm{L-1}$, por $\mathrm{HNO}_{3} 1 \mathrm{~mol} \mathrm{L-1}$ fervente e por HF concentrado, conforme descrito em Pratt (1973).

Com vistas em estudar a dessor ção de potássio dos solos, utilizou-se uma resina trocadora de cátions (IR120), com uma capacidade de troca de $18 \mathrm{mmol}_{\mathrm{C}} \mathrm{kg}^{-1}$. A resina foi, previamente, imersa em solução de $\mathrm{HCl}$ 1 mol L-1, por 48 horas e, após, lavada, sucessivamente, com solução $\mathrm{HCl}$ 0,1 mol L-1 e água deionizada até estar livre de cloro. A resina saturada de prótons foi mantida imersa em água deionizada antes de ser utilizada. A liberação do potássio para a resina $\mathrm{H}^{+}$ saturada foi feita, em duas repetições, pelo equilíbrio de um grama de sol oseco peneirado ( $<2 \mathrm{~mm}$ ), col ocado em tubo de centrífuga, juntamente com dois gramas de resina e $20 \mathrm{~mL}$ de água deionizada. A mistura soloresina-água foi deixada em equilíbrio, a intervalos de tempo, variando desde um minuto até 2.400 horas $(0,0167,0,050,0,10,0,20,24,72,144,312,600,1.158$ e 2.400 horas), e foi agitada, a cada dia, levemente (manualmente). Ao fim de cada período de reação, a resina foi separada dos solos por centrifugação, e o potássio adsorvido a ela foi extraído com solução de $\mathrm{NH}_{4} \mathrm{Cl} 1 \mathrm{~mol} \mathrm{L-1}$. O teor de potássio nos extratos foi determinado por fotometria de chama.

Equações matemáticas (parabólica de difusão, de primeira-ordem, potencial e de Elovich) foram testadas, por análise de regressão, para determinar qual delas melhor descreve a cinética de dessor ção do potássio dos sol os estudados em função do tempo. Para cada equação, cal cularam-se o coeficiente de correlação ( $r)$ e o erro-padrão da estimativa $(E P)$, definido por: $E P=\left[S\left(K t-K t^{*}\right)^{2} /(n-2)\right]^{1 / 2}$, sendo $K t$ e Kt* as concentrações de potássio dessorvidas, medidas e calculadas, respectivamente, no tempo t, e $\mathbf{n}$ é o número de observações (J ardine \& Sparks 1984). As 
análises estatísticas foram realizadas por meio do procedimento GLM (General Linear Models) do SAS (1988).

\section{RESULTADOS E DISCUSSÃO}

\section{Liberação do potássio trocável}

A quantidade de potássio liberado dos três solos, nos 12 minutos iniciais de equilíbrio com a resina catiônica (Figura 1), foi considerada como a fração K trocável, considerando a inflexão acentuada das curvas neste tempo e a declividade das retas de dessorção dos 12 minutos até às 24 horas, que permaneceu, praticamente, a mesma. O K trocável liberado no vertissolo $\left(273 \mathrm{mg} \mathrm{kg}^{-1}\right)$ foi superior ao liberado pelo latossolo (198 $\mathrm{mg} \mathrm{kg}^{-1}$ ) e pelo podzólico (151 mg kg-1). Para os dois últimos sol os, os teores de $\mathrm{K}$ trocável foram semel hantes aos extraídos pelo $\mathrm{NH}_{4} \mathrm{OAC} 1$ mol L-1 a pH 7; no vertissolo, entretanto, o $\mathrm{K}$ trocável liberado para a resina correspondeu a $81 \%$ do extraído pelo $\mathrm{NH}_{4} \mathrm{OAc}$ (Quadro 1). Nesse solo, possivel mente, pela predominância deargil ominerais do tipo 2:1 (Meurer et al., 1996), o íon $\mathrm{NH}_{4}{ }^{+}$, com raio iônico semel hante ao do potássio, pode ter deslocado potássio (não trocável) das entrecamadas dos argilominerais, superestimando, assim, a quantidade de $\mathrm{K}$ trocável. Os íons $\mathrm{NH}_{4}{ }^{+}$podem formar complexos de esfera-interna, bem como deslocar outros cátions das entrecamadas de argilominerais 2:1 (Sposito, 1989).

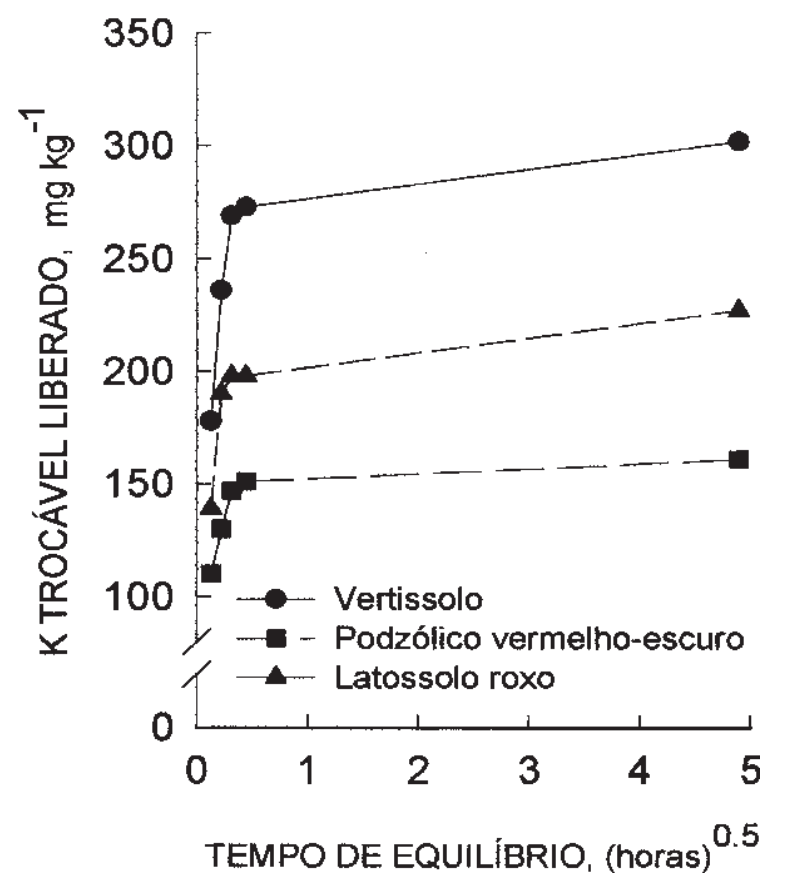

Figura 1. Liberação cumulativa de $K$ trocável dos solos em função do tempo de equilíbrio com a resina.
Quadro 1. Algumas características dos horizontes A $(0-20 \mathrm{~cm})$ dos solos estudados

\begin{tabular}{|c|c|c|c|}
\hline Características & Vertissolo & $\begin{array}{c}\text { Podzólico } \\
\text { vermelho-escuro }\end{array}$ & $\begin{array}{l}\text { Latossolo } \\
\text { roxo }\end{array}$ \\
\hline Material de origem & folhelho & granito & basalto \\
\hline Areia, $\mathrm{g} \mathrm{kg}^{-1}$ & 210 & 470 & 30 \\
\hline Silte, $\mathrm{g} \mathrm{kg}^{-1}$ & 340 & 200 & 140 \\
\hline Argila $2-0,2 \mu \mathrm{m}, \mathrm{g} \mathrm{kg}^{-1}$ & 170 & 70 & 240 \\
\hline Argila $<0,2 \mu \mathrm{m}, \mathrm{g} \mathrm{kg}^{-1}$ & 280 & 260 & 590 \\
\hline pH água & 5,1 & 5,0 & 5,0 \\
\hline $\mathrm{P}$ extraível, $\mathrm{mg} \mathrm{kg}^{-1}$ & 12 & 7 & 8 \\
\hline $\mathrm{K}_{\text {total }}{ }^{(1)}, \mathrm{mg} \mathrm{kg}^{-1}$ & 12.277 & 3.015 & 1.878 \\
\hline $\mathrm{K}$ não trocável ${ }^{(2)}, \mathrm{mg} \mathrm{kg}^{-1}$ & 1.364 & 465 & 231 \\
\hline $\mathrm{K}_{\text {trocável }}{ }^{(3)}, \mathrm{mg} \mathrm{kg}^{-1}$ & 336 & 152 & 224 \\
\hline Matéria orgânica, $\mathrm{g} \mathrm{kg}^{-1}$ & 35 & 20 & 26 \\
\hline CTC, mmol $_{\mathrm{C}} \mathrm{kg}^{-1}$ & 184 & 57 & 78 \\
\hline
\end{tabular}

(1) Extração com ácido fluorídrico e posterior dissolução em $\mathrm{HCl}$ $6 \mathrm{~mol} \mathrm{~L}^{-1}$ (Pratt, 1973). (2) Extração com $\mathrm{HNO}_{3} 1 \mathrm{~mol} \mathrm{~L}^{-1}$ fervente (Pratt, 1973). (3) Extração com N H${ }_{4} \mathrm{OAc} 1$ mol L-1 pH 7 (Pratt, 1973).

\section{Liberação do potássio não-trocável}

A quantidade de $\mathrm{K}$ não-trocável dessorvida no vertissolo (436 $\mathrm{mg} \mathrm{kg}^{-1}$ ) foi muito maior do que a no podzólico (64 $\mathrm{mg} \mathrm{kg}^{-1}$ ) e no latossolo (46 $\left.\mathrm{mg} \mathrm{kg}^{-1}\right)$ (Figura 2). É possível quea mineralogia (Quadro 2) e os teores de K total desses sol os possam explicar esses resultados: o vertissolo apresenta maiores quantidades de potássio ( $K$ total), de quatro a seis vezes maior do que a do podzólico e a do latossolo (Quadro 1), respectivamente. Os teores mais el evados de potássio no vertissolo podem ser devidos à dominância de argilominerais 2:1, como mica e interestratificado mica-vermiculita com hidroxi-Al entrecamadas (VHE) ou mica-esmectita e esmectita com hidroxi-entrecamadas; esses minerais podem ser fontes de $\mathrm{K}$ não-trocável, conforme constatado por Harris et al. (1988), Wada et al. (1991) e Wada \& Kakuto (1993). Por anal ogia, isso também poderia ser o caso da vermiculita com hidroxi-Al entrecamadas, no podzólico, ou da esmectita com hidroxi-Al entrecamadas, no latossolo. A declividade das curvas de dessorção do potássio, nos três solos (Figuras 2a e b), indica que, possivelmente, quantidades expressivas deK não-trocável poderiam ser liberadas do vertissolo e do podzólico num maior tempo de equilíbrio com a resina; nolatossolo, por outrolado, a curva indica uma tendência de estabilização.

As quantidades de K não-trocável dessorvidas dos três solos nas 2.400 horas de equilíbrio com a resina foram acentuadamente inferiores àquelas extraídas pela solução de $\mathrm{HNO}_{3} 1 \mathrm{~mol} \mathrm{L-1}$ fervente (Quadro 1). Não se pode, entretanto, descartar a hipótese de que, num tempo maior de equilíbrio dos solos com a resina, possa haver maior liberação de K não-trocável desses sol os, aproximando-se aos val ores extraídos pel oácido 
Quadro 2. Princi pais minerais que ocorrem nas frações areia, silte e argila dos horizontes A de três solos do Estado do Rio Grande do Sul

\begin{tabular}{|c|c|c|c|}
\hline \multirow{2}{*}{ Solos } & \multicolumn{3}{|r|}{ Mineral $^{(1)}$} \\
\hline & Areia & Silte & Argila $^{(2)}$ \\
\hline Vertissolo & $\mathrm{Qz}, \mathrm{fd}, \mathrm{mi}$ & $\mathrm{Qz}, \mathrm{fd}, \mathrm{mi}$ & Es, ve, mi, mi-ve, mi-es, vhe, ehe, i-mi-vhe, i-mi-ehe \\
\hline Podzólico vermelho-escuro & $\mathrm{Qz}, \mathrm{fd}, \mathrm{mi}$ & $\mathrm{Qz}, \mathrm{ka}, \mathrm{fd}, \mathrm{mi}$ & Ka, mi, vhe, mi-vhe, \\
\hline Latossolo roxo & $\mathrm{Qz}, \mathrm{fd}, \mathrm{mi}, \mathrm{mg}$ & $\mathrm{Qz}, \mathrm{ka}, \mathrm{fd}, \mathrm{gb}$ & $\mathrm{Ka}$, ehe \\
\hline
\end{tabular}

(1) A letra inicial maiúscula identifica o mineral predominante na fração; Qz = quartzo, fd = feldspato, mi = mica, ka = caulinita, gb = gibbsita, mg = magnetita, es = esmectita, ve = vermiculita, vhe = vermiculita com hidroxi-Al entrecamadas, ehe = esmectita com hidroxi-Al entrecamadas, i-mi-vhe = interestratificado mica-vermiculita com hidroxi-Al entrecamadas, i-mi-ehe = interestratificado mica-esmectita com hidroxi-Al entrecamadas. ${ }^{(2)}$ Fração isenta de óxidos de ferro.

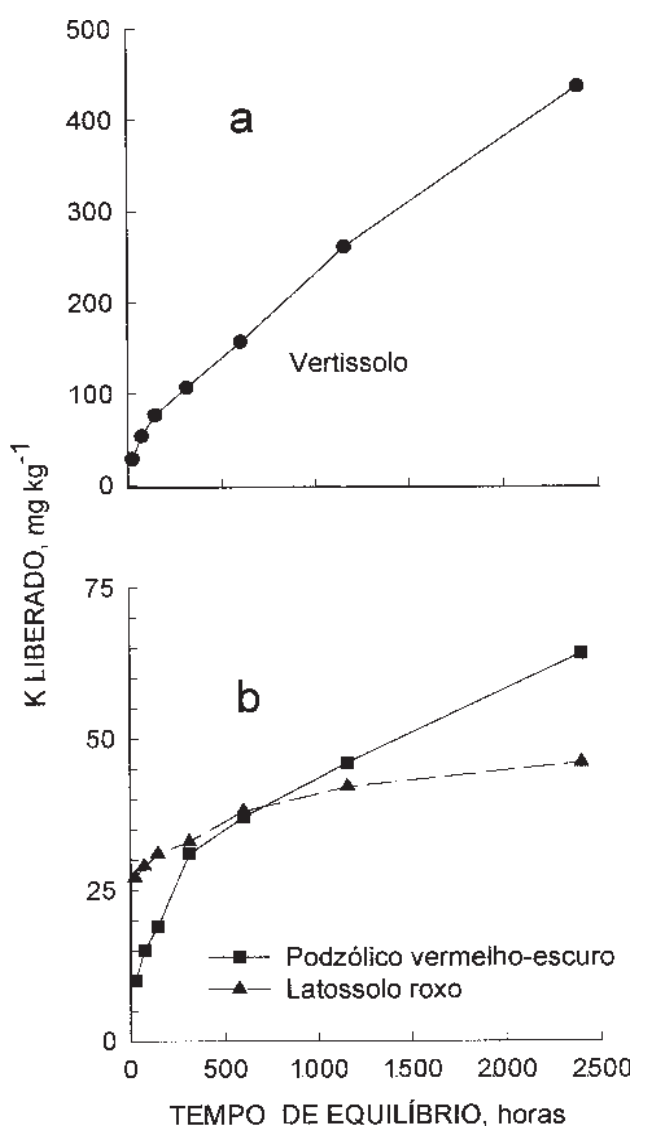

Figura 2. Liberação cumulativa de K não-trocável em função do tempo de equilíbrio (a) no vertissolo e (b) no podzólico vermelho-escuro e no latossolo roxo.

nítrico. $\mathrm{O} \mathrm{HNO}_{3}$ apresenta desvantagem, como outros ácidos fortes, pela capacidade potencial para dissolver potássio estrutural, podendo, dessa forma, superestimar o K não-trocável (Martin \& Sparks, 1985). Silva et al . (1995) encontraram que o potássio extraído por solução de $\mathrm{HNO}_{3} 1 \mathrm{~mol} \mathrm{~L}^{-1}$ foi de pouca utilidade para o entendimento da dinâmica das formas não trocáveis depotássio, em experimentos no campo, desenvol vidos por dez anos em latossolos do Estado do Paraná.

\section{Comparação de equações para descrever a cinética de li beração do potássio}

Todas as equações descreveram, com maior ou menor erro na estimativa, a liberação do potássio nos solos (Quadro 3). De acordo com os valores do $r$ (coeficiente de correlação) e do EP (erro-padrão da estimativa), a equação parabólica de difusão foi a que melhor descreveu a dessorção do potássio dos solos para a solução de equilíbrio. O ajuste da equação parabólica aos dados (Figura 3) indica que o mecanismo de dessor ção de potássio, nesses solos, seria um fenômeno controlado por difusão: os íons $\mathrm{K}^{+}$se difundiriam do interior das partículas doargilomineral para a superfície ou da superfície para a solução. Outros pesquisadores usaram equações parabólicas de difusão, para descrever a cinética das reações dos constituintes dos solos (Quirk \& Chute, 1967; Talibudeen \& Weir,1972; Sparks \& J ardine, 1981; J ardine \& Sparks, 1984; Havlin et al., 1985; Elkhatib \& Hern, 1988; Dhillon et al., 1989). Os valores para as taxas constantes (b) deliberação do K não-trocável foram de 2,09 × 10-2 h-1, para o vertissolo; de 1,89 × 10-2 h-1, para o podzólico, e de 0,97 × 10-2 h-1, para o latossolo (Figura 3) e são semel hantes aos valores obtidos por Dhillon \& Dhillon (1990) para solos da Índia. A baixa taxa de liberação de potássio no latossolo pode estar relacionada com a esmectita com hidroxi-Al entrecamadas (EHE) da argila, fração que contém 76\% do potássio total desse solo e que pode ser a fonte do potássio não-trocável (Meurer et al., 1996).

Estudos mais detalhados sobre a cinética de dessorção de potássio em solos com diferentes propriedades físicas, químicas e mineralógicas e sua relação com a disponibilidade e absorção do potássio pelas plantas fornecerão subsídios para fazer predições mais adequadas da liberação do K dos solos e, conseqüentemente, tornar mais apropriadas as recomendações de fertilização potássica. A escolha da equação mais apropriada para descrever a liberação de potássio do solo, entretanto, somente poderá ser definida após o estabelecimento de relações estreitas entre os coeficientes dessas equações e a absorção do potássio pelas plantas. Havlin \& Westfall (1985) e Mengel \& Uhlenbecker (1993), por exemplo, observaram quea equação potencial foi mais adequada 
Quadro 3. Coeficientes de correlação ( $r$ ) e erro-padrão da estimativa (E $P$ ) das equações usadas para descrever a dessorção do potássio não-trocável do solos

\begin{tabular}{|c|c|c|c|c|c|c|}
\hline \multirow[t]{2}{*}{ Equação } & \multicolumn{2}{|c|}{ Vertissolo } & \multicolumn{2}{|c|}{ Podzólico vermelho-escuro } & \multicolumn{2}{|c|}{ Latossolo } \\
\hline & $\mathbf{r}$ & EP & $\mathbf{r}$ & EP & $\mathbf{r}$ & EP \\
\hline Parabólica de difusão $\mathrm{Kt} / \mathrm{K}_{\infty}=\mathrm{a}+\mathrm{bt}^{1 / 2}$ & 0,989 & 0,053 & 0,994 & 0,035 & 0,989 & 0,025 \\
\hline Primeira-Ordem $\ln \left(K_{\infty}-K t\right)=a-b t$ & 0,996 & 0,031 & 0,980 & 0,093 & 0,998 & 0,043 \\
\hline Potência $\ln \mathrm{Kt}=\ln \mathrm{a}+\mathrm{b} \ln (\mathrm{t})$ & 0,996 & 0,094 & 0,996 & 0,060 & 0,982 & 0,040 \\
\hline Elovich $\mathrm{Kt}=\mathrm{a}+\mathrm{b} \ln (\mathrm{t})$ & 0,898 & 69,40 & 0,966 & 5,424 & 0,970 & 1,883 \\
\hline
\end{tabular}

$\mathrm{Kt}=$ quantidade de potássio dessorvida no tempo $\mathrm{t} ; \mathrm{K}_{\infty}=$ quantidade de potássio dessorvida após $2.400 \mathrm{~h}$ de equilíbrio.

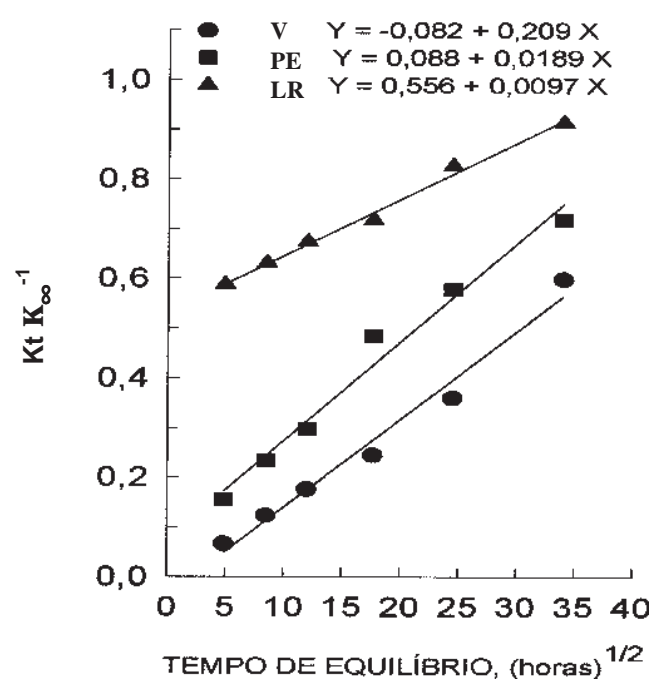

Figura 3. Cinética de liberação do potássio nãotrocável dos solos, descrita pela equação parabólica de difusão $(\mathrm{V}=$ vertissolo, $\mathrm{PE}=$ podzólico vermelho-escuro, LR =latossolo roxo).

para fornecer informações sobre a capacidade de suprimento de potássio dos solos que trabalharam, pois as constantes "a" e "b" dessa equação se correlacionaram, positivamente, com o teor inicial de $\mathrm{K}$ trocável do solos. As mesmas constantes também se correlacionaram, significativamente, com as quantidades de K trocável e de K não-trocável absorvidas pela cultura da alfafa.

\section{CONCLUSÕES}

1. As quantidades cumulativas de potássio nãotrocável liberadas dos sol os e as respectivas taxas de liberação decresceram na seqüência vertissolo > podzólico > latossolo.

2. A equação parabólica de difusão foi a mais apropriada para descrever a cinética de liberação de potássio dos solos, pelo maior valor do coeficiente de correlação e pelo menor valor do erro-padrão da estimativa.

\section{LITERATURA CITADA}

BRASIL. Ministério da Agricultura. Levantamento de Reconhecimento dos solos do Estado do Rio Grande do Sul. Recife, 1973. 431p. (Boletim Técnico, 30)

CRISÓSTOMO, L.A. \& CASTRO, A.F. Poder de suprimento de potássio de sol os da zona fisiográfica de Baturité, CE, Brasil. Turrialba, Costa Rica, 20:425-433, 1970.

COMERFORD, N.B.; HARRIS, W.G. \& LUCAS, D. Release of nonexchangeable potassium from a highly weathered forest Quartzipsamment. Soil Sci. Soc. Am. J., Madison, 54:14211426, 1990.

DHILLON, S.K. \& DHILLON, K.S. Kinetics of realease of nonexchangeable potassium by cation satured resins from red (Alfisols), black (Vertisols) and alluvial (Inceptisols) soils of India. Geoderma, Amsterdam, 47:283-300, 1990

DHILLON, S.K., SIDHU, P.S.; \& BANSAL, R.C. Release of potassium from some benchmark soils of India. J. Soil Sci., London, 40:783-797, 1989.

ELKHATIB, E.A. \& HERN, J.L. Kinetics of potassium desorption from Appalachian soils. Soil Sci., Baltimore, 145:11-19, 1988.

HARRIS, W.G.; HOLLIEN, K.A.; YUAN, T.L.; BATES, S.R. \& ACREE, W.A. Nonexchangeable potassium associated with hydroxy-interlayered vermiculite from Coastal Plain Soils. Soil Sci. Soc. Am. J., Madison, 52:1486-1492, 1988.

HAVLIN, J.L.; WESTFALL, D.G. \& OLSEN, S.R. Mathematical models for potassium rel ease kinetics in calcareous soils. Soil Sci. Soc. Am. J., Madison, 49:371-376, 1985.

HAVLIN, J.L. \& WESTFALL, D.G. Potassium kinetics and plant response in calcareous soils. Soil Sci. Soc. Am. J., Madison, 49:366-370, 1985.

J ARDINE, P.M. \& SPARKS, D.L. Potassium-calcium exchange in a multivariate soil system: I. Kinetics. Soil Sci. Soc. Am. J ., Madison, 48:39-45, 1984.

KAUFFMAN, M.D. \& BOULDIN, D.R. Relationships of exchangeable and non-exchangeable potassium in soils adjacent to cation-exchange resins and plant roots. Soil Sci., Baltimore, 104:145-150, 1967

MARTIN, H.W. \& SPARKS, D.L. Kinetics of nonexchangeable potassium realease from two Coastal Plain soils. Soil Sci. Soc. Am. J., Madison, 47:883-887, 1983. 
MARTIN, H.W. \& SPARKS, D.L. On the behavior of nonexchangeable potassium in soils. Comm. Soil Plan. Anal., New York, 16:133-162, 1985.

MENGEL,K.\&UHLENBECKER, K. Determinations of avalilable interlayer potassium and its uptake by ryegrass. Soil Sci. Soc. Am. J., Madison, 57:761-766, 1993.

MEURER, E.J .; KÄMPF, N. \& ANGHINONI, I. Fontes potenciais de potássio em alguns solos do Rio Grande do Sul. R. bras. Ci. Solo, Campinas, 20:41-47, 1996.

MIELNICZUK, J . \& SELBACH, P.A. Capacidade de suprimento de potássio de seis solos do Rio Grande do Sul . R. Bras. Ci. Solo, Campinas, 2:115-20, 1978.

NACHTIGALL, G.R. \& VAHL, L.C. Capacidade de suprimento de potássio dos solos da Região Sul do Rio Grande do Sul. R. bras. Ci. Solo, Campinas, 15:37-42, 1991.

OLIVEIRA, V.; LUDWICK, A.E. \& BEATTY, M.T. Potassium removed from some southern Brazilian soils by exhaustive cropping and chemical extractions methods. Soil Sci. Soc. Am. Proc., Madison, 35:763-767, 1971.

PRATT, P.F. Potassium. In: BLACK, C.A., ed. Methods of soil analysis. Part 1. Madison, American Society of Agronomy, 1973. p.1022-1032. (Agronomy Series, 9)

QUIRK, J.P. \& CHUTE, J.H. Potassium release from mica like clay minerals. In: INTERNATIONAL CONGRESS OF SOIL SCIENCE, 9., Adelaide, 1968. Proceedings. Adelaide, International Society of Soil Science, 1967. p.671-682.

SADUSKY, M.C.; SPARKS, D.L.; NOLL, M.R. \& HENDRICKS G.J. Kinetics and mechanisms of potassium release from sandy Middle Atlantic Coastal Plain Soils. Soil Sci. Soc. Am. J., Madison. 51:1460-1465, 1987.
SAS I nstitute I nc. SAS/STAT U ser's Guide, Release 6.03 Edition. Cary, NC:SAS I nstitute Inc., 1988. 1028p.

SHARPLEY, A.N. The Kinetics of soil potassium desorption. Soil Sci. Soc.Am.J ., Madison, 51:912-917, 1987.

SILVA, D.N.; MEURER, E.J .; KÄMPF, N. \& BORKERT, C.M. Mineral ogia e formas de potássio em dois latossol os do estado do Paraná e suas relações com a disponibilidade para as plantas. R. bras. Ci. Solo, Campinas, 19:433-439. 1995.

SIMARD, R.R.; KIMPE, C.R. \& ZIZKA, J. Release of potassium and magnesium from soil fractions and its kinetics. Soil Sci. Soc. Am. J., Madison, 56:1421-1428, 1992.

SPARKS, D.L. \& J ARDINE, P.M. Comparison of kinetics equations to describe K-Ca exchange in pure and mixed systems. Soil Sci. Soc. Am. J., Madison, 45:1094-1099, 1984.

SPARKS, D.L. Kinetics of soil chemical processes. California, Academic Press, 1989. 210p.

SPOSITO, G. The chemistry of soils. New York, Oxford University Press., 1989. 277p.

TALIBUDEEN, O. \& WEIR, A.H. Potassium reserves in a 'Harvwell' series soil. J .Soil Sci., London, 23:456-474, 1972.

TEDESCO, M.J .; VOLKWEISS, S.J . \& BOHNEN, H. Análises de solos, plantas e outros materiais. PortoAlegre, UFRGS., 1985. 188p. (Boletim Técnico, 5)

WADA, K. \& KAKUTO, Y. Nonexchangeable potassium in a 1.4nanometer mineral and mica in a Korean Ultisol. Soil Sci.Soc.Am.J ., Madison, 57:552-557, 1993.

WADA, K.; KAKUTO, Y.; WILSON, M.A. \& HANNA, J.V. The chemical composition and structure of a $14 \AA$ intergradient mineral in a Korean Ultisol. Clay Min., Clarkson, 26:449461, 1991. 